\title{
Aurafuron A and B, New Bioactive Polyketides from Stigmatella aurantiaca and Archangium gephyra (Myxobacteria)
}

\author{
Fermentation, Isolation, Physico-chemical Properties, Structure and \\ Biological Activity ${ }^{\dagger}$
}

Brigitte Kunze, Hans Reichenbach, Rolf Müller, Gerhard Höfle

Received: February 15, 2005 / Accepted: March 24, 2005

(C) Japan Antibiotics Research Association

\begin{abstract}
New antibiotic polyketides, named aurafuron A (1) and B (2) were isolated from culture extracts of myxobacteria of the species Stigmatella aurantiaca and Archangium gephyra, strain Ar 10844. By multi-step chromatography $\mathbf{1}$ and $\mathbf{2}$ were separated from a variety of other non-related co-metabolites, and their structures elucidated by spectroscopic methods as new 5-alkenyl-3 $3(2 H)$-furanones. Aurafurons inhibited the growth of some filamentous fungi and additionally, aurafuron B was weakly active against few Gram-positive bacteria. Both compounds also showed cytotoxic activity against the mouse fibroblast cell line L929.
\end{abstract}

Keywords Myxobacteria, bioactive polyketides, 5alkenyl-3 3(2H)-furanones, aurafurons

\section{Introduction}

In the course of our continuous screening for new bioactive metabolites, strains of the genus Stigmatella emerged to be secondary metabolite multiproducing myxobacteria. For example $S$. aurantiaca strain DW4/3-1 simultaneously produces the electron transport inhibitor myxothiazol [1], the dawenols [2], the myxochromides [3], and the iron chelators myxochelin A and B $[4,5]$. In culture extracts of S. aurantiaca, strain $\mathrm{Sg}$ a15 even five structurally entirely different groups of metabolites have been discovered, namely the inhibitors of the eukaryotic electron transport, the aurachins [6], stigmatellins [7, 8], and myxalamids [7, 9, 10], and as in strain DW4/3-1 also the myxochelins [5] and minor amounts of myxochromides components [3]. Recently by genetic studies a variety of typical secondary metabolic gene clusters encoding multimodular polyketide synthases (PKS) and non-ribosomal peptide synthetases (NRPS) have been identified in both $S$. aurantiaca, DW4/3-1 $[3,11,12]$, and $S$. aurantiaca, Sg a15 [5, 13 16]. Some of those gene clusters were shown to be responsible for the formation of the known secondary metabolites, others may be used for the biosynthesis of novel natural products whose structures are yet to be determined.

As a result of both detailed HPLC-DAD analysis of culture extracts and molecular biosynthetic studies with $S$. aurantiaca we here describe the production, isolation,
B. Kunze (Corresponding author), H. Reichenbach, G. Höfle: GBF, German Research Centre for Biotechnology, Department of Natural Products Mascheroder Weg 1, D-38124 Braunschweig, Germany, E-mail: bku@gbf.de

R. Müller: Institut für Pharmazeutische Biotechnologie, Universität des Saarlandes, Im Stadtwald, D- 66123 Saarbrücken, Germany
${ }^{\dagger}$ Article No. 102 on antibiotics from gliding bacteria. Article No. 101: Wenzel SC, Kunze B, Höfle G, Silakowski B, Scharfe M, Blöcker H, Müller R. ChemBioChem 6: 375-385 (2005) 
<smiles>CC1=C(C[C@@H](O)/C=C/C=C/C(C)[C@H](O)/C(C)=C/CC(C)C)OC(C)(O)C1=O</smiles>

aurafuron $\mathrm{A}(1)$<smiles>CC1=C(/C=C/C=C/C=C/C(C)[C@H](O)/C(C)=C/CC(C)C)OC(C)(O)C1=O</smiles>

(8Z)-aurafuron B (2a)<smiles>CC(C)=CCC(C)=CC=CC=CC=CC=CC1=C(C)C(=O)C(C)(O)O1</smiles>

$(8 E)$-aurafuron $B(2 b)$

Fig. 1 Structures of aurafuron A (1) and B (2a, 2b). For C12 and $\mathrm{C}-13$ only the relative configuration is shown.

physico-chemical properties, structure elucidation as well as the biological activity of the new aurafurons A (1) and B (2) (Fig. 1). In addition to strains of the genus Stigmatella, the new compounds have also been isolated from a strain of the genus Archangium. Both genera belong to the family Cystobacteraceae, and strains of the genus Archangium are also known to produce a variety of secondary metabolites with biological activity [17]. Among these, due to their potential as anticancer drugs, particularly the tubulysins $[18,19]$, have attracted great attention.

\section{Results}

\section{Fermentation and Isolation}

Because of the fact that aurafuron A and aurafuron B showed completely different UV spectra during examination of crude extracts with diode-array-detected (DAD) RP-HPLC they were isolated and characterized from different species on different occasions. An analytical HPLC/DAD profile of fermenter culture extracts of A. gephyra Ar 10844 and S. aurantiaca DW4/3-1 is given in Fig. 2.

For the production of aurafuron A (1), strain Ar 10844 was selected which, compared to strain DW4/3-1, produced by far less and smaller amounts of other non-related metabolites (Fig. 2). Large-scale fermentations were performed in M7 liquid medium with the addition of $1 \%$ of
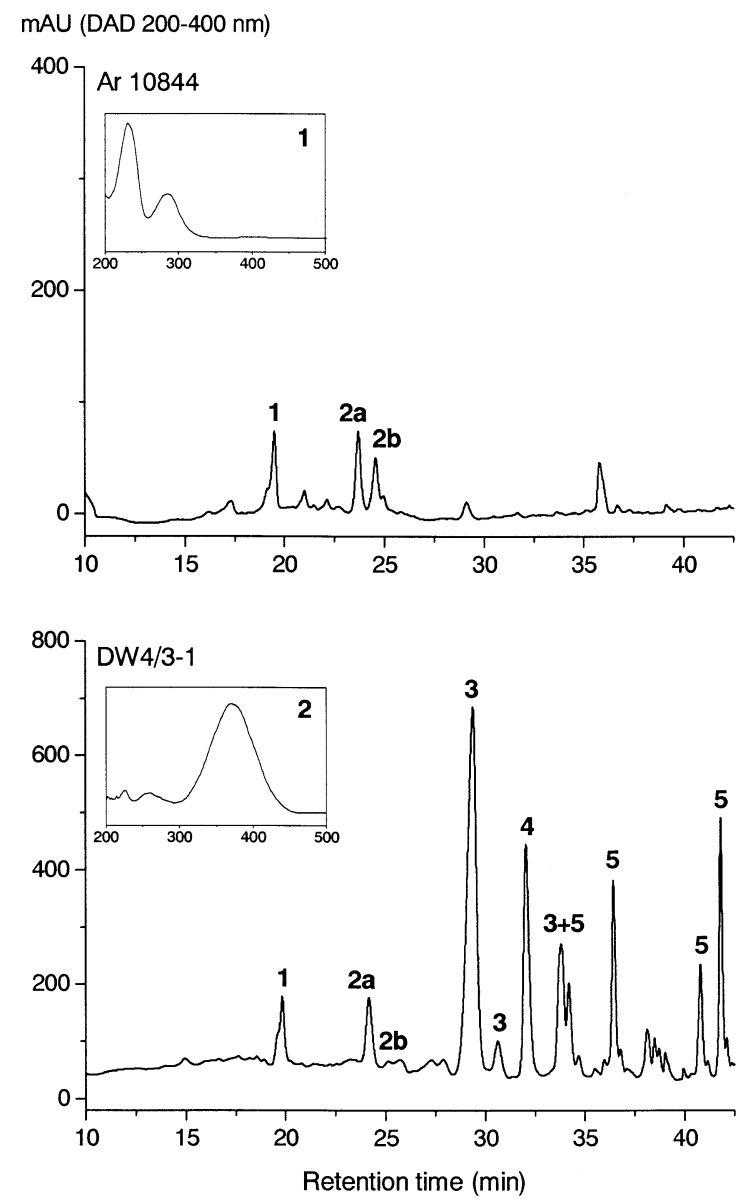

Fig. 2 HPLC analysis of crude extracts from the fermentation of Archangium gephyra Ar 10844 and Stigmatella aurantiaca DW4/3-1, and overlaid UV spectra from aurafuron $A(\mathbf{1})$ and $B(2)$. 1 aurafuron $A, \mathbf{2 a}, \mathbf{2 b}$ aurafuron B, 3 myxochromides, 4 myxothiazol A, 5 dawenols.

the adsorber resin Amberlite XAD-16. In a 280-liter fermentation batch described in the experimental section, 1 accumulated till the end of the fermentation at 68 hours up to about $2.4 \mathrm{mg} /$ liter as analyzed by HPLC. Isolation and purification was achieved by extraction, solvent partition and multi-step chromatography yielding $260 \mathrm{mg}$ of pure aurafuron A.

For the isolation of aurafuron B (2) fermentations of strain DW4/3-1 were used, which were originally run for the production of other metabolites, e.g., the dawenols [2] and the myxochromides [3]. These were performed in 150 liters bioreactors containing 85 liters Zein liquid medium with $1 \%$ of the adsorber resin Amberlite XAD-16 as described in detail previously [2, 3]. A 90-liter fermentation was harvested 70 hours after inoculation and aurafuron B (2) was isolated from the fermenter crude 
Table 1 Physico-chemical properties of aurafuron A (1) and (8Z)-aurafuron B (2a)

\begin{tabular}{|c|c|c|}
\hline & Aurafuron A & (8Z)-Aurafuron B \\
\hline Appearance & Yellow oil & Yellow oil \\
\hline$[\alpha]_{D}(\mathrm{MeOH})$ & -40.5 & -72.9 \\
\hline Molecular weight & 378 & 360 \\
\hline Molecular formula & $\mathrm{C}_{22} \mathrm{H}_{34} \mathrm{O}_{5}$ & $\mathrm{C}_{22} \mathrm{H}_{32} \mathrm{O}_{4}$ \\
\hline ESI-MS $(\mathrm{M}-\mathrm{H})^{-}$ & 377 & 359 \\
\hline \multicolumn{3}{|l|}{$\mathrm{HRDCl}-\mathrm{MS}\left(\mathrm{NH}_{3}\right) \mathrm{m} / \mathrm{z}$} \\
\hline Calcd. for $\mathrm{C}_{22} \mathrm{H}_{38} \mathrm{NO}_{5}\left(\mathrm{M}+\mathrm{NH}_{4}+\right)$ & 396.2750 & \\
\hline Found & 369.2794 & \\
\hline \multicolumn{3}{|l|}{ HREI-MS $m / z$} \\
\hline Calcd. for $\mathrm{C}_{22} \mathrm{H}_{32} \mathrm{O}_{4}$ & & 360.2301 \\
\hline Found & & 360.2290 \\
\hline UV $\lambda_{\max }(\mathrm{MeOH}), \mathrm{nm}(\varepsilon)$ & 231 (14960), 281 (6850) & 259 (5900), 369 (33500) \\
\hline $\mathrm{IR}(\mathrm{KBr}) \mathrm{cm}^{-1}$ & 1696,1616 & 1682,1601 \\
\hline TLC ${ }^{a}$ Rf-value & 0.4 & 0.59 \\
\hline $\mathrm{HPLC}^{\mathrm{b}}$ retention time & 19.9 minutes & 24.1 minutes \\
\hline
\end{tabular}

a Silica gel Si $60 \mathrm{~F}_{254}$ aluminium sheets (Merck). Solvent: $\mathrm{CH}_{2} \mathrm{Cl}_{2} /$ acetone/MeOH $(75: 20: 5)$. Detection: UV absorption at $254 \mathrm{~nm}$ and staining with cerium (IV) sulfate/phosphomolybdic acid in sulphuric acid and heating to $120^{\circ} \mathrm{C}$, giving blue spots; The Rf-value for (8E)-aurafuron B (2b) was 0.64 .

${ }^{b}$ See experimental section; the retention time for $(8 E)$-aurafuron $\mathrm{B}(\mathbf{2} \mathbf{b})$ was 25.1 minutes.

extract as described below yielding $220 \mathrm{mg}$ of crude aurafurons from which pure $16 \mathrm{mg}(8 Z)$ isomer $\mathbf{2 a}$ and $2 \mathrm{mg}(8 E)$-isomer $\mathbf{2 b}$ were obtained by RP chromatography.

\section{Physico-chemical Properties and Structure}

The physico-chemical properties of aurafuron A (1) and (8Z)-aurafuron B (2a) are summarized in Table 1. Structure elucidation is best started with $\mathbf{2 a}$ which, in contrast to $\mathbf{1}$, shows simple NMR signal patterns (Tables 2 and 3). From NMR data and HREI mass spectra the elemental composition $\mathrm{C}_{22} \mathrm{H}_{32} \mathrm{O}_{4}$ is deduced accounting for 7 double bond equivalents. Analysis of proton and carbon spectra including 2D correlated spectra (not shown) straightforward revealed the structure of an unsaturated hydroxy and methyl substituted alkyl chain. Its $6 E, 8 Z, 10 E$ configuration follows from vicinal proton coupling constants, whereas $14 E$ configuration is indicated by a strong NOEs between $22-\mathrm{H}_{3}$ and $16-\mathrm{H}_{2}$, and $13-\mathrm{H}$ and $15-$ $\mathrm{H}$. The remaining molecular fragment $\mathrm{C}_{6} \mathrm{H}_{7} \mathrm{O}_{3}$ consists of two methyl groups appearing as singlets, a quaternary acetal carbon at $103.9 \mathrm{ppm}$ and three carbonyl/olefinic signals at 206.0, 178.7 and $109.5 \mathrm{ppm}$. From the various combinations of these building blocks only a $3(2 H)$ furanone is consistent with the $\mathrm{C}, \mathrm{H}$-correlated NMR spectra. In addition, the IR spectrum with bands for carbonyl and double bonds at 1682 and $1601 \mathrm{~cm}^{-1}$ and UV bands for a $\beta$-oxyenenone and an extended double bond system from C-3 to C-11 at 259 and $369 \mathrm{~nm}$ are in full accordance with the proposed structure. The minor isomer 2b differs only by an $8 E$ double bond resulting in a $15 \mathrm{~Hz}$ vicinal coupling constant between $8-\mathrm{H}$ and $9-\mathrm{H}$. In sharp contrast, aurafuron A (1) differs significantly from B (2) by a shift of IR and UV bands to shorter wavelengths indicating interruption of the conjugated double bond system. In addition, most NMR signals appear doubled. From the elemental composition a double bond was replaced by a hydroxyethylene group, which has to be placed in 6,7-position according to the proton NMR spectrum. All three aurafurons, 1, 2a and $\mathbf{2 b}$ obviously exist as 1:1 mixtures of stereoisomers at the $\mathrm{C}-2$ hemiacetal centre. However, only in aurafuron A the next stereocenter, $\mathrm{C}-7$, is close enough to cause signal doubling for the diastereomers present. The absolute $(S)$ configuration of C7 was determined by ozonolysis. Only L-malic acid was detected by chiral GC analysis. The relative anti configuration at $\mathrm{C}-12$ and $\mathrm{C}-13$ follows from the vicinal coupling of the respective protons by $8.3 \mathrm{~Hz}$ as it was observed with myxalamids [10].

\section{Biological Activity}

As shown in Table 4, aurafuron A (1) and B (2) showed moderate activity against some filamentous fungi. Additionally, (8Z)-aurafuron B (2a) showed weak activity against a few Gram-positive bacteria. In individual cases 
Table $2{ }^{1} \mathrm{H}$ data of aurafuron $\mathrm{A}(\mathbf{1})$ and $(8 Z)$-aurafuron $\mathrm{B}(\mathbf{2 a})$ and $(8 E)$-aurafuron $\mathrm{B}(\mathbf{2} \mathbf{b})$ in $\mathrm{CD}_{3} \mathrm{OD}$

\begin{tabular}{|c|c|c|c|c|c|c|c|c|c|c|}
\hline \multicolumn{4}{|c|}{1} & \multicolumn{4}{|c|}{$2 a$} & \multicolumn{3}{|c|}{$2 b$} \\
\hline Atom & $\delta(\mathrm{ppm})$ & Multipl. & $J_{H, H}(H z)$ & Atom & $\delta(\mathrm{ppm})$ & Multipl. & $J_{H, H}(H z)$ & $\delta(\mathrm{ppm})$ & Multipl. & $J_{H, H}(H z)$ \\
\hline $1-\mathrm{H}_{3}$ & $\begin{array}{l}1.44 \\
1.47\end{array}$ & & & $1-\mathrm{H}_{3}$ & 1.53 & s & & 1.53 & s & \\
\hline $6-\mathrm{Ha}$ & 2.65 & $\mathrm{dd}$ & $13.6 ; 6.5$ & $6-\mathrm{H}$ & 6.61 & $d$ & 14.7 & 6.58 & $d$ & 15.3 \\
\hline $6-\mathrm{Hb}$ & 2.94 & $\mathrm{dd}$ & $13.6 ; 7.2$ & & & & & & & \\
\hline 6- $\mathrm{Ha}$ & 2.77 & $\mathrm{dd}$ & $13.7 ; 6.7$ & & & & & & & \\
\hline $6-\mathrm{Hb}$ & 2.86 & $\mathrm{dd}$ & $13.7 ; 6.7$ & & & & & & & \\
\hline $7-\mathrm{H}$ & $\begin{array}{l}5.02 \\
5.03\end{array}$ & $\mathrm{~m}$ & & $7-\mathrm{H}$ & 7.74 & $\mathrm{dd}$ & $14.7 ; 12.1$ & 7.28 & $\mathrm{dd}$ & $15.1 ; 10.3$ \\
\hline $8-\mathrm{H}$ & $\begin{array}{l}6.36 \\
6.38\end{array}$ & $\begin{array}{l}t \\
t\end{array}$ & $\begin{array}{l}10.2 \\
10.2\end{array}$ & $8-\mathrm{H}$ & 6.21 & t & 11.3 & 6.31 & $\mathrm{dd}$ & $15.3 ; 10.7$ \\
\hline $9-\mathrm{H}$ & $\begin{array}{l}6.08 \\
6.10\end{array}$ & $\begin{array}{l}\mathrm{t} \\
\mathrm{t}\end{array}$ & $\begin{array}{l}11.0 \\
11.0\end{array}$ & $9-\mathrm{H}$ & 6.44 & $t$ & 11.1 & 6.46 & dd & $14.9 ; 11.3$ \\
\hline $10-\mathrm{H}$ & $\begin{array}{l}6.41 \\
6.44\end{array}$ & $\begin{array}{l}d d \\
d d\end{array}$ & $\begin{array}{l}15.0 ; 11.4 \\
15.0 ; 11.4\end{array}$ & $10-\mathrm{H}$ & 6.78 & $d d$ & $14.4 ; 12.1$ & 6.71 & dd & $14.8 ; 10.7$ \\
\hline $11-\mathrm{H}$ & $\begin{array}{l}5.79 \\
5.80\end{array}$ & $\begin{array}{l}d d \\
d d\end{array}$ & $\begin{array}{l}15.1 ; 8.0 \\
15.1 ; 8.0\end{array}$ & $11-\mathrm{H}$ & 6.04 & $\mathrm{dd}$ & $14.9 ; 8.1$ & 6.08 & $d d$ & $15.1 ; 8.0$ \\
\hline $12-\mathrm{H}$ & 2.42 & sextett & 7.3 & $12-\mathrm{H}$ & 2.54 & sextett & 7.2 & 2.54 & sextett & 7.2 \\
\hline $13-\mathrm{H}$ & 3.72 & d & 8.4 & $13-\mathrm{H}$ & 3.79 & d & 8.3 & 3.79 & d & 8.3 \\
\hline $15-\mathrm{H}$ & 5.44 & $\mathrm{t}$ & 7.4 & $15-\mathrm{H}$ & 5.46 & t & 7.2 & 5.46 & $\mathrm{t}$ & 7.2 \\
\hline $\begin{array}{l}16-\mathrm{H} \\
17-\mathrm{H}\end{array}$ & $\begin{array}{l}1.98 \\
1.67\end{array}$ & $\mathrm{t}$ & 7.0 & $\begin{array}{l}16-\mathrm{H}_{2} \\
17-\mathrm{H}\end{array}$ & $\begin{array}{l}2.00 \\
1.68\end{array}$ & $\mathrm{t}$ & 7.0 & $\begin{array}{l}2.00 \\
1.68\end{array}$ & $\mathrm{t}$ & 7.0 \\
\hline $18-\mathrm{H}$ & 0.95 & $d$ & 6.6 & $18-\mathrm{H}_{3}$ & 0.95 & $d$ & 6.8 & 0.95 & $d$ & 6.8 \\
\hline $19-\mathrm{H}$ & 0.96 & $d$ & 6.6 & $19-\mathrm{H}_{3}$ & 0.96 & $d$ & 6.8 & 0.96 & $d$ & 6.8 \\
\hline $20-\mathrm{H}$ & $\begin{array}{l}1.70 \\
1.72\end{array}$ & $\begin{array}{l}\mathrm{s} \\
\mathrm{s}\end{array}$ & & $20-\mathrm{H}_{3}$ & 1.79 & s & & 1.79 & s & \\
\hline $21-\mathrm{H}$ & $\begin{array}{l}0.91 \\
0.92\end{array}$ & $\begin{array}{l}d \\
d\end{array}$ & $\begin{array}{l}6.9 \\
6.9\end{array}$ & $21-\mathrm{H}_{3}$ & 1.00 & $d$ & 7.2 & 1.00 & $d$ & 7.2 \\
\hline $22-\mathrm{H}_{3}$ & 1.63 & sbr & & $22-\mathrm{H}_{3}$ & 1.65 & $\mathrm{sbr}$ & & 1.65 & sbr & \\
\hline
\end{tabular}

the inhibitory activity of aurafurons was stronger when the test organisms were cultivated in minimal media, as demonstrated for the representative test organism Mucor hiemalis. When grown in minimal medium, the minimum inhibitory concentrations (MIC) of aurafuron A and B for M. hiemalis were $6.3 \mu \mathrm{g} / \mathrm{ml}$. The compounds also proved to be cytotoxic. The $\mathrm{IC}_{50}$ for cultivated $\mathrm{L} 929$ mouse fibroblasts was $4 \mu \mathrm{g} / \mathrm{ml}$ for $\mathbf{1}$ and $0.35 \mu \mathrm{g} / \mathrm{ml}$ for $\mathbf{2 a}$.

\section{Discussion}

Our screening of more than 60 strains of Stigmatella aurantiaca showed that 11 of these strains synthesize aurafurons, as identified by HPLC-DAD analysis. All of those strains produce simultaneously myxothiazol
A, myxochromides and dawenols. Compared to these co-metabolites, the aurafurons were produced in each case only in minor amounts as described for strain DW 4/3-1 (Fig. 2). Within the genus Archangium, from approximately 240 strains exclusively strain Ar 10844 produced aurafurons. The structures of aurafurons have as characteristic features a $3(2 H)$-furanone ring system as 2 hemiacetal and an unsaturated C-5 side-chain, and thus show a close relationship to polypropionates isolated from the marine molluscs of the genus Siphonaria [20 25]. Further structural relationships exist to the natural compound AS-183, which was isolated from the fungus Scedosporium sp. strain SPC-15549 and was shown to inhibit acyl-CoA: cholesterol acyltransferase (ACAT) of rabbit liver microsomes [26]. 
Table $3{ }^{13} \mathrm{C}$ NMR chemical shifts of aurafuron A (1) and (8Z)-aurafuron B (2a)

\begin{tabular}{lccr}
\hline & $\mathbf{1}$ & \\
Atom & * (ppm) & $\mathbf{2 a}$ \\
\cline { 2 - 3 } C-1 & $22.2,22.3$ & \\
\hline C-2 & $104.1,104.2$ & 22.4 \\
C-3 & $205.1,205.2$ & 103.9 \\
C-4 & $110.1,110.2$ & 206.0 \\
C-5 & $185.6,185.7$ & 109.5 \\
C-6 & $38.3,38.5$ & 178.7 \\
C-7 & $66.0,66.1$ & 118.6 \\
C-8 & $126.2,126.3$ & 135.3 \\
C-9 & $131.0,131.4$ & 126.8 \\
C-10 & $131.6,131.9$ & 139.2 \\
C-11 & $141.5,141.6$ & 126.7 \\
C-12 & $41.8,41.9$ & 145.0 \\
C-13 & 83.3 & 42.2 \\
C-14 & 137.6 & 83.1 \\
C-15 & $128.0,128.1$ & 137.6 \\
C-16 & 37.8 & 127.9 \\
C-17 & $30.0,30.7$ & 37.8 \\
C-18 & 22.8 & 30.0 \\
C-19 & 22.9 & 22.9 \\
C-20 & 5.8 & 11.7 \\
C-21 & $17.7,17.8$ & \\
C-22 & 11.5 & \\
\hline & & \\
\hline
\end{tabular}

\section{Experimental}

\section{General}

Optical rotation was determined on a Perkin Elmer 241 MC polarimeter. UV and IR spectra were recorded on a Shimadzu UV/Vis-2102 PC spectrometer and Nicolet 20DXB FT-IR spectrometer respectively. NMR spectra were recorded with a Bruker ARX 400 and AM 300 spectrometer $\left({ }^{1} \mathrm{H}: 400.1 \mathrm{MHz},{ }^{13} \mathrm{C}\right.$ : 100.6 and $\left.75.5 \mathrm{MHz}\right)$ using the solvent signal as internal standard. EI- and DCIMS spectra were recorded with a Finnigan spectrometer MAT 95 (resolution $M / \Delta M=1000$; high-resolution data from peak matching, $M / \Delta M=10000$ ), ESI-MS spectra with a Sciex Api 2000 LC/MS/MS.

\section{Producing Organisms and Culture Conditions}

Archangium gephyra strain Ar10844 was isolated at the GBF from a soil sample collected in 1998 near Ubud on Bali, Indonesia. It belongs to those myxobacteria that live by degrading proteins and even whole cells of other microorganisms. Thus Archangium strains could best be obtained by inoculating streaks of living Escherichia coli on plain water agar with small bits of a soil sample. Details of this and other isolation procedures have been described by H. Reichenbach and M. Dworkin [27]. Stigmatella aurantiaca DW4/3-1 was kindly provided by Prof. Dr. David White (Bloomington, Indiana). For maintenance both strains were grown on VY/2 agar plates (bakers' yeast $0.5 \%, \mathrm{CaCl}_{2} \cdot 2 \mathrm{H}_{2} \mathrm{O} 0.1 \%$, cyanocobalamine $0.5 \mu \mathrm{g} / \mathrm{ml}$, agar $1.5 \%, \mathrm{pH} 7.2$ ). In liquid cultures strain Ar 10844 was grown in M7 liquid medium consisting of Probion (single cell protein prepared from Methylomonas clarae; Hoechst A.G.) $0.5 \%$, starch $0.5 \%$, glucose $0.2 \%$, yeast extract $0.1 \%$, $\mathrm{MgSO}_{4} \cdot 7 \mathrm{H}_{2} \mathrm{O} 0.1 \%, \mathrm{CaCl}_{2} \cdot 2 \mathrm{H}_{2} \mathrm{O} 0.1 \%$, cyanocobalamine $0.1 \mathrm{mg} /$ liter, HEPES buffer $1 \%$, pH 7.4. Strain DW 4/3-1 was cultured in tryptone liquid medium containing tryptone $1 \%, \mathrm{MgSO}_{4} \cdot 7 \mathrm{H}_{2} \mathrm{O} \quad 0.2 \%$, pH 7.2, and in media based on technical substrates, e.g., Probion or Zein [2]. Batch cultures of $100 \mathrm{ml}$ or of $400 \mathrm{ml}$ in $250-\mathrm{ml}$ or $1,000-\mathrm{ml}$ Erlenmeyer flasks, respectively, were incubated at $30^{\circ} \mathrm{C}$ on a gyratory shaker at $160 \mathrm{rpm}$ for $3 \sim 5$ days. Stock cultures were stored in a deep freezer at $-80^{\circ} \mathrm{C}$ or in liquid nitrogen.

\section{Fermentation and Isolation of Aurafuron A from A. gephyra, Ar 10844}

Large-scale fermentations were performed in M7 liquid medium (modification $10 \mathrm{mM}$ HEPES, $\mathrm{pH}$ 7.0) to which $1 \%(\mathrm{v} / \mathrm{v})$ of the adsorber resin Amberlite XAD-16 (Rohm \& Haas, Frankfurt, Germany) had been added before sterilization. A 350-liter bioreactor (Giovanola Frères, Monthey, Switzerland; periphery modified by GBF) containing 280-liter of modified M7 medium (see above) was inoculated with 5.2 liters of shaking cultures grown for 3 days in M7 liquid medium. The bioreactor was kept at $30^{\circ} \mathrm{C}$, aerated at $0.05 \mathrm{vvm}$ per minute and agitated with a flat-blade turbine stirrer at $100 \mathrm{rpm}$. The $\mathrm{pH}$ value rose till the end of the fermentation after 68 hours from 7.0 to 7.5. The $\mathrm{pO} 2$, recorded with a polarographic oxygen electrode was around $95 \%$ saturation at the beginning of the fermentation and dropped to about $5 \%$ after 32 hours; it then fluctuated between $5 \%$ and $0 \%$ till the end of the fermentation. Foam formation could be suppressed by addition of $100 \mathrm{ml}$ of a 30\% antifoam emulsion (Dow Corning, USA) to the medium before sterilization.

At the end of the fermentation the adsorber resin and the cell mass were collected with a sieve and by centrifugation, respectively. Both were extracted separately with 5 and 8.5 liters of acetone, respectively. The content of aurafuron A in the XAD and cell extracts was estimated by HPLC to be $0.6 \mathrm{~g}$ and $0.2 \mathrm{~g}$, respectively. The combined extracts were concentrated in vacuo to 3.5 liters of an aqueous phase. 
Table 4 Aurafurons: biological activity

\begin{tabular}{|c|c|c|}
\hline \multirow{2}{*}{ Test organisms ${ }^{a}$} & \multicolumn{2}{|c|}{ Diameter of inhibition zone $(\mathrm{mm})^{\mathrm{b}}$} \\
\hline & Aurafuron A & Aurafuron B \\
\hline Escherichia coli DSM 423 & 0 & 0 \\
\hline Bacillus subtilis DSM 10 & 0 & 0 \\
\hline Corynebacterium fascians DSM 20131 & 0 & $\operatorname{tr}$ \\
\hline Corynebacterium fascians ${ }^{\complement}$ DSM 20131 & 0 & 12 \\
\hline Micrococcus luteus ${ }^{c}$ GBF 26 & 0 & $\operatorname{tr}$ \\
\hline Staphylococcus aureus GBF 16 & 0 & $\operatorname{tr}$ \\
\hline Candida albicans GBF 129 & 0 & 0 \\
\hline Saccharomyces cerevisiae ${ }^{d}$ GBF 36 & 0 & 0 \\
\hline Aspergillus fumigatus & $(\mathrm{tr})$ & (9) \\
\hline Botrytis cinerea DSM 877 & 0 & 11 \\
\hline Botrytis cinerea DSM $877^{c}$ & 0 & $\operatorname{tr}$ \\
\hline Gibberella fujikuroi DSM 893 & 0 & 0 \\
\hline Mucor hiemalis DSM 2655 & (17) & (20) \\
\hline Mucor hiemalis DSM $2655^{\circ}$ & 22 & 25 \\
\hline Trichoderma koningii DSM 63060 & (17) & (24) \\
\hline Ustilago maydis & 0 & (9) \\
\hline
\end{tabular}

\footnotetext{
${ }^{a}$ The organism were tested on standard complex media. ${ }^{b}$ Determined by the agar diffusion test with $20 \mu \mathrm{g}$ aurafurons per 6-mm paper disc. Figures in parentheses indicate an incomplete inhibition. ${ }^{\mathrm{c}}$ The organism was cultivated in minimal media. ${ }^{d}$ The organism was cultivated in a medium containing $2 \%$ glycerol instead of glucose.
}

After $\mathrm{pH}$ phase adjustment to 5.5 with $\mathrm{KH}_{2} \mathrm{PO}_{4}$ the liquid was extracted 3 times with 1 liter of ethyl acetate. The organic phase was evaporated in vacuo and the residue distributed between heptane ( 0.5 liter) and methanol (1 liter). From the methanol phase $18 \mathrm{~g}$ of crude extract was obtained and further separated by chromatography on a silica gel column $(300 \mathrm{~g}, 63 \sim 200 \mu \mathrm{m})$ with a dichloromethane/methanol gradient from $99: 1$ to $90: 10$ (5.5 liters). Aurafuron containing fractions were identified by TLC (Table 1, footnote a), combined and evaporated to give $2.18 \mathrm{~g}$ of oil. This enriched material was further separated in 2 runs by RP chromatography (HD-Sil18-20$60 ; 7 \times 50 \mathrm{~cm}$, methanol $/ 10 \mathrm{mM}$ ammonium acetate buffer $8: 2$, detection $227 \mathrm{~nm}$ ). A first fraction of $165 \mathrm{mg}$ of impure and a second fraction of $260 \mathrm{mg}$ of pure aurafuron A were obtained as yellow oil.

\section{Fermentation and Isolation of Aurafuron B from S. aurantiaca, DW 4/3-1}

Batch fermentations of strain DW4/3-1 were carried out in a 150-liter bioreactor (Bioengineering, Wald, Switzerland) containing 85 liters Zein liquid medium (Zein 0.8\%, peptone from casein tryptically digested $0.1 \%$, $\mathrm{MgSO}_{4} \cdot 7 \mathrm{H}_{2} \mathrm{O} 1$, HEPES $10 \mathrm{mM}$, XAD-16 1\%, pH 7.2) as described [2]. The fermenter was inoculated with 5 liters of well grown shaking cultures, and the fermentation was carried out for 70 hours at $30^{\circ} \mathrm{C}$ with an aeration rate of 7.41 iters air per minute and an agitation of $110 \sim 180 \mathrm{rpm}$ with a flat-blade stirrer.

At the end of the fermentation the cell mass and the Amberlite XAD 16 adsorber resin from the culture broth were eluted with acetone and methanol, respectively. The combined eluates were concentrated in vacuo resulting in an aqueous layer, which was extracted with ethyl acetate. Evaporation of the solvent yielded a dark oily residue ( $32 \mathrm{~g}$ ) that was partitioned between methanol (1.5 liter) and heptane (1 liter). The concentrated methanol layer $(29 \mathrm{~g})$ was fractionated on a LH-20 column $(10 \times 100 \mathrm{~cm}$, methanol, 15 fractions) and according to TLC (Table 1 , footnote a), fractions 7 and $8(5.4 \mathrm{~g})$ contained myxochromides and aurafurons. Silica gel chromatography of $3.3 \mathrm{~g}$ of this mixture $(70 \mathrm{~g}$ silica gel $25 \sim 40 \mu \mathrm{m}$, dichloromethane/methanol gradient $100: 0$ to $90: 10$ ) gave $220 \mathrm{mg}$ of crude aurafurons which were further purified by RP chromatography (Nucleodur C-18, methanol/water $78: 22$, detection $340 \mathrm{~nm}$ ) to give $16 \mathrm{mg}$ of (8Z)-aurafuron B (2A) and $2 \mathrm{mg}(7 E)$-aurafuron B (2B).

\section{Degradation of Aurafuron A}

A solution of $1 \mathrm{mg}$ of $\mathbf{1} \mathrm{in} 1 \mathrm{ml}$ of methanol was ozonized 
at -60 degrees, $0.1 \mathrm{ml}$ of $0.1 \mathrm{mM} \mathrm{NaOH}$ and $20 \mu \mathrm{l}$ of $30 \%$ $\mathrm{H}_{2} \mathrm{O}_{2}$ were added and boiled shortly. Excess peroxides were destroyed with $\mathrm{Pt} / \mathrm{C}$, and the methanol evaporated. After acidification it was extracted with butanol, the butanol was evaporated and the residue stirred with diethyl ether, $20 \mu \mathrm{l}$ of methyl iodide and $100 \mathrm{mg}$ of silver oxide over night. GC analysis on a Hepatakis-(2,6-di-o-methyl-3-o-pentyl)- $\beta$ cyclodextrin column and co-chromatography with authentic samples indicated the presence of permethylated L-malic acid.

\section{Analysis of Secondary Metabolites}

The spectrum of secondary metabolites produced by the different strains was determined in aliquots of concentrated acetone extracts by diode-array-detected HPLC analysis using a Hewlett Packard series 1100 instrument. Chromatographic conditions were as follows: Column ET $125 \times 2 \mathrm{~mm}$ and precolumn, Nucleosil 120-5C18. The solvent was methanol/water $45: 55$ (A)/methanol (B); isocratic conditions were $0 \% \mathrm{~B}$ for the first 7 minutes, then a gradient up to $45 \% \mathrm{~B}$ at 20 minutes, followed by isocratic conditions of $45 \%$ B for 6 minutes (the time point was 26 minutes in the HPLC run), followed by a gradient up to $81.8 \% \mathrm{~B}$ at 40 minutes; the flow rate was $0.5 \mathrm{ml} /$ minute and detection was at $200 \sim 400 \mathrm{~nm}$.

\section{Biological Assays}

Standard strains for testing the biological activity spectrum were obtained from the Deutsche Sammlung von Mikroorganismen (DMSZ) and the stock collection of our laboratory at the GBF.

The antimicrobial spectrum of aurafuron A (1) and B (2a) was determined by an agar-plate diffusion assay. From a sample of $1 \mathrm{mg} / \mathrm{ml} 20 \mu \mathrm{l}$ aliquots were applied to filter disks of $6 \mathrm{~mm}$ diameter. The test plates were incubated for 24 48 hours at the temperature that permitted optimal growth of the test organisms. To determine the minimal inhibition concentrations of $\mathbf{1}$ and $\mathbf{2}$, the conventional serial two-fold dilution method was used. $1.6 \times 10^{5}$ spores $/ \mathrm{ml}$ were used as inoculum, and the antibiotics were dissolved in methanol, giving $\mathrm{MeOH}$ concentrations in the cultures of not more than 3\%. Growth inhibition was evaluated after incubation 48 hours. Cytotoxicity against L929 cells (mouse, connective tissue, ATCC CCL 1) was determined as reported [28].

Acknowledgments The authors wish to thank Prof. Dr. David White who kindly provided $S$. aurantiaca strain DW 4/3-1.They also like to thank B. Engelhardt, M. Weilharter and K. Schober for their skillful assistance, A. Roß, H. Schüler, R. Krützfeld and coworkers for their contribution in large scale fermentation and downstream processing, and Dr. V. Wray and co-workers of the Department of Structural Research for NMR and mass spectra. They are also grateful to Dr. F. Sasse for performing the mammalian cell culture tests.

\section{References}

1. Thierbach G, Reichenbach H. Myxothiazol, a new inhibitor of the cytochrome $b-c_{1}$ segment of the respiratory chain. Biochim Biophys Acta 638: 282-289 (1981)

2. Söker U, Kunze B, Reichenbach H, Höfle G. Dawenol, a new polyene metabolite from the myxobacterium Stigmatella aurantiaca. Z. Naturforsch. 58b: 1024-1026 (2003)

3. Wenzel SC, Kunze B, Höfle G, Silakowski B, Scharfe M, Blöcker H, Müller R. Structure and biosynthesis of myxochromides $\mathrm{S}_{1-3}$ in Stigmatella aurantiaca: Evidence for an iterative bacterial type I polyketide synthase and for module skipping in nonribosomal peptide biosynthesis. ChemBio Chem 6: 375-385 (2005)

4. Kunze B, Bedorf N, Kohl W, Höfle G, Reichenbach H. Myxochelin A, a new iron chelating compound from Angiococcus disciformis (Myxobacterales). Production, isolation, physico-chemical and biological properties. J Antibiot 42: 14-17 (1989)

5. Silakowski B, Kunze B, Nordsiek G, Blöcker H, Höfle G, Müller R. The myxochelin iron transport regulon of the myxobacterium Stigmatella aurantiaca Sg a15. Eur J Biochem 267: 1-11 (2000)

6. Kunze B, Höfle G, Reichenbach H. The aurachins, new quinoline antibiotics from myxobacteria: production, physico-chemical and biological properties. J Antibiot 40: 258-265 (1987)

7. Kunze B, Kemmer T, Höfle G, Reichenbach H. Stigmatellin a new antibiotic from Stigmatella aurantiaca (Myxobacterales). I. Production, physico-chemical and biological properties. J Antibiot 37: 454-461 (1984)

8. Höfle G, Kunze B, Zorzin C, Reichenbach H. Antibiotika aus gleitenden Bakterien, XXIII. Stigmatellin A und B-zwei neue Antibiotika aus Stigmatella aurantiaca (Myxobacterales). Liebigs Ann Chem 1984: 1883-1904 (1984)

9. Gerth K, Jansen R, Reifenstahl G, Höfle G, Irschik H, Kunze B, Reichenbach H, Thierbach G. The myxalamids, new antibiotics from Myxococcus xanthus (Myxobacterales). I. Production, physico-chemical and biological properties, and mechanism of action. J Antibiot 36: 1150-1156 (1983)

10. Jansen R, Reifenstahl G, Gerth K, Reichenbach H, Höfle G. Myxalamide A, B, C und D; eine Gruppe homologer Antibiotika aus Myxococcus xanthus Mx x12 (Myxobacterales). Liebigs Ann Chem 1983: 1081-1095 (1983)

11. Silakowski B, Schairer HU, Ehret H, Kunze B, Weinig S, Nordsiek G, Brandt P, Blöcker H, Höfle G, Beyer S, Müller 
R. New lessons for combinatorial biosynthesis from myxobacteria: the myxothiazol biosynthetic gene cluster of Stigmatella aurantiaca DW4/3-1. J Biol Chem 274: 37391-37399 (1999)

12. Silakowski B, Kunze B, Müller R. Multiple hybrid polyketide synthase/non ribosomal peptide synthetase gene clusters in the myxobacterium Stigmatella aurantiaca. Gene 275: 233-240 (2001)

13. Beyer S, Kunze B, Silakowski B, Müller R. Metabolic diversity in myxobacteria: identification of the myxalamid and the stigmatellin biosynthetic gene cluster of Stigmatella aurantiaca $\mathrm{Sg}$ a15 and a combined polyketide-(poly) peptide gene cluster from the epothilone producing strain Sorangium cellulosum So ce90. Biochim Biophys Acta 1445: 185-195 (1999)

14. Silakowski B, Kunze B, Müller R. Stigmatella aurantiaca Sg a15 carries genes encoding type I and type II 3-deoxy-Darabino-heptulosonate-7-phospate synthases. Involvement of a type II synthase in aurachin biosynthesis. Arch Microbiol 173: 403-411 (2000)

15. Silakowski B, Nordsiek G, Kunze B, Blöcker H, Müller R. Novel features in a combined polyketide synthase/nonribosomal peptide synthetase: the myxalamid biosynthetic gene cluster of the myxobacterium Stigmatella aurantiaca Sg a15. Chem Biol 8: 59-69 (2001)

16. Gaitatzis N, Silakowski B, Kunze B, Nordsiek G, Blöcker H, Höfle G, Müller R. The biosynthesis of the aromatic myxobacterial electron transport inhibitor stigmatellin is directed by a novel type of modular polyketide synthase. J Biol Chem 277: 13082-13090 (2002)

17. Sasse F, Steinmetz H, Höfle G, Reichenbach H. Archazolids, new cytotoxic macrolactones from Archangium gephyra (Myxobacteria). Production, isolation, physico-chemical and biological properties. J Antibiot 56: 520-525 (2003)

18. Sasse F, Steinmetz H, Heil J, Höfle G, Reichenbach H. Tubulysins, new cytostatic peptides from myxobacteria acting on microtubuli. Production, isolation, physico- chemical and biological properties. J Antibiot 53: 879-885 (2000)

19. Steinmetz H, Glaser N, Herdtweck E, Sasse F, Reichenbach $\mathrm{H}$, Höfle G. Isolation, crystal and solution structure determination, and biosynthesis of tubulysins - powerful inhibitors of tubulin polymerisation from myxobacteria. Angew Chem 116: 4996-5000 (2004)

20. Capon RJ, Faulkner DJ. Metabolites of the pulmonate Siphonaria lessoni. J Org Chem 49: 2506-2508 (1984)

21. Cimino G, Sodano G, Spinella A. New propionate-derived metabolites from Aglaja depicta and from its prey Bulla striate (Opisthobranch Molluscs). J Org Chem 52: 5326-5331 (1987)

22. Norte M, Cataldo F, González GAG, Rodríguez ML, RuizPerez C. New metabolites from the marine mollusc Siphonaria grisea. Tetrahedron 46: 1669-1678 (1990)

23. Norte M, Fernandez JJ, Padilla A. Isolation and synthesis of siphonarienal a new polypropionate from Siphonaria grisea. Tetrahedron Lett 35: 3413-3416 (1994)

24. Paul MC, Zubia E, Ortega MJ, Salvá J. New polypropionates from Siphonaria pectinata. Tetrahedron 53: 2303-2308 (1997)

25. Beukes DR, Davies-Coleman MT. Novel polypropionates from the south african marine mollusc Siphonaria capensis. Tetrahedron 55: 4051-4056 (1999)

26. Kuroda K, Yoshida M, Uosaki Y, Ando K, Kawamoto I, Oishi E, Onuma H, Yamada K, Matsuda Y. AS-183, a novel inhibitor of acyl-CoA: cholesterol acyltransferase produced by Scedosporium sp. SPC-15549. J Antibiot 46: 1196-1202 (1993)

27. Reichenbach H, Dworkin M. The myxobacteria. In: A. Balows, et al. (ed.). The Prokaryotes, 2nd ed., Vol. 4. Springer Verlag, New York, pp. 3416-3487 (1992)

28. Mosmann T. Rapid colorimetric assay for cellular growth and survival: Application to proliferation and cytotoxic assays. J Immunol Methods 65: 55-63 (1983) 